\title{
Falas entrecruzadas, o viés feminista na produção midiática de Clarice Lispector
}

Intertwined speeches, feminist bias in Clarice Lispector's media production

\author{
Aparecida Maria Nunes ${ }^{1}$
}

\begin{abstract}
RESUMO
$\mathrm{O}$ artigo analisa a produção acadêmica de Clarice Lispector publicada na revista $A$ Época de 1941 , bem como as narrativas que compõem a página "Entre Mulheres", do tabloide Comício de 1952. É possível reconhecer nesses textos a preocupação da escritora com os papéis femininos e a influência de Simone de Beauvoir em seu pensamento, ao divulgar, de forma velada, trechos que traduz de Le Deuxième Sexe.
\end{abstract}

PALAVRAS-CHAVE: Clarice Lispector. Feminismo. A Época. Comício. Simone de Beauvoir.

\begin{abstract}
The article analyzes the academic production of Clarice Lispector published in the magazine A Época of 1941, as well as the narratives that compose the page "Entre Mulheres", of the tabloid Comicio of 1952. It is possible to recognize in these texts the concern of the writer with the feminine roles and the influence of Simone de Beauvoir in her thought, by disseminating, in a veiling way, excerpts that translates from Le Deuxième Sexe.

KEYWORDS: Clarice Lispector. Feminism. A Época. Comício. Simone de Beauvoir.

$$
* * *
$$
\end{abstract}

1941. Clarice Lispector está no terceiro ano da Faculdade Nacional de Direito da Universidade do Brasil, quando publica dois artigos assinados na revista acadêmica $A$ Época, da qual é então redatora: "Observações sobre o fundamento do direito de punir", em agosto, e "Deve a mulher trabalhar?", em setembro.

\footnotetext{
${ }^{1}$ Aparecida Maria Nunes, mestre e doutora em Literatura Brasileira pela Universidade de São Paulo. Pós-doutora em Estudos Literários pela Universidade Federal de Minas Gerais. Professora associada do curso de Letras e do Programa de Pós-graduação em História Ibérica, da Universidade Federal de Alfenas, Minas Gerais, Brasil. E-mail: cydamaria@gmail.com
} 
Ambos os escritos não são muito comentados em trabalhos de pesquisa. ${ }^{2}$ Talvez por não apresentarem o apuro textual e o caráter intimista que destacam a produção da ficcionista consagrada. Clarice também, nessa ocasião, ainda é uma jovem universitária de 21 anos, que está inclinada a se dedicar à carreira jornalística, porque percebe que jamais irá conseguir reformular as penitenciárias, como é seu desejo, acalentado desde a infância. Temos ainda nessa ocasião uma escritora em formação, que se vale da imprensa para publicar alguns de seus contos e poemas. Mas, em A Época, podemos perceber que as ideias que movem a Clarice Lispector escritora já estão à mostra e começam a ganhar contorno, principalmente para definir a linha editorial que adotará nos anos 1950 e início dos 1960 ao produzir suas colunas femininas.

Os dois textos veiculados na revista discente, no entanto, denotam o perfil de uma estudante com opiniões próprias, até ousadas, podemos considerar, a ponto de compartilhar com leitores uma visão crítica destoante da mentalidade daqueles anos, ainda submetidos ao período autoritário do Estado Novo (1937-1945) de Getúlio Vargas e aos conflitos da Segunda Guerra Mundial (1939-1945). Aliás, ao ocupar o cargo de redatora de A Época, Clarice demonstra estar engajada com projetos acadêmicos, além de compactuar com a natureza política da publicação, ligada ao Centro Acadêmico Cândido de Oliveira - $\mathrm{Caco}^{3}$ - um dos redutos da luta antifascista de então.

A revista A Época circula de 1906 a 1960 e é distribuída em todas as escolas de Direito do país, divulgando artigos assinados por nomes representativos da intelectualidade da Faculdade Nacional. Na década de

\footnotetext{
2 Os textos de Clarice Lispector na imprensa brasileira, pela primeira vez, foram resgatados e analisados por Aparecida Maria Nunes, em trabalhos de pós-graduação na Universidade de São Paulo, nas décadas de 1980 e 1990. Mais tarde, parte dessa pesquisa de mestrado e doutorado foi publicada em livros. Para consultar os primeiros textos na íntegra de Clarice Lispector em jornais e revistas cariocas, duas publicações são importantes: Clarice na Cabeceira: Jornalismo (Rocco) e Clarice Lispector Jornalista: Páginas Femininas \& Outras Páginas (Senac/SP).

3 O Caco participou de várias campanhas estudantis e populares. As mais representativas são: a mobilização para a entrada do Brasil na Segunda Guerra Mundial, a luta em defesa do monopólio estatal da exploração do petróleo no início da década de 1950 e, em 1959, o apoio à decisão do presidente Juscelino Kubitschek de não atender às exigências do Fundo Monetário Internacional (FMI), por contrariarem a política nacional-desenvolvimentista do governo.

Cf. http://www.fgv.br/Cpdoc/Acervo/dicionarios/verbete-tematico/centro-academico-candido-deoliveira-caco
} 
1940, período marcado por constantes manifestações estudantis, notadamente a resistência ao Estado Novo, a Faculdade é transferida para a Rua Moncorvo Filho, onde Clarice estuda.

Portanto, a fim de contextualizar o período em que Clarice Lispector inicia, digamos assim, sua carreira na imprensa carioca, alguns dados biográficos da escritora são necessários, bem como a caracterização da estudante que foi, que, conforme estudos nossos, molda já a linha ideológica pautada por Clarice em sua produção jornalística e literária.

Ao concluir, em 1938, o curso complementar de Direito no Colégio Andrews, Clarice presta na sequência os exames para o ingresso da turma de 1939, na Escola Nacional de Direito da Universidade do Brasil. Entre os colegas de classe, obtém a primeira classificação. E é aprovada em quarto lugar geral, concorrendo com trezentos candidatos. Essa informação consta no curriculum vitae da escritora ${ }^{4}$, o que demonstra a importância dessa conquista em sua vida estudantil. Apesar da excelente classificação para um curso de vocação masculina e de bem relacionada, a jovem estudante, tempos depois, percebe não se sentir atraída pela profissão de bacharel ${ }^{5}$, como mencionamos. Desiludida, pensa em desistir. Mas resolve concluir o curso, desafiada, quando estava no terceiro ano, por uma amiga que lhe disse que ela jamais termina o que começa. O fato é que Clarice se mantém como boa aluna, destacando-se apenas com brilhantismo em algumas disciplinas, como a de Direito Penal, sua preferida. Justamente pelo ambiente universitário e pelo contato com professores, cuja rede de sociabilidade inclui jornalistas, políticos, escritores e intelectuais influentes, Clarice Lispector passa a ter contato com personalidades que, certamente, a influenciam em leituras e reflexões.

Mas a passagem pela faculdade de Direito parece estar sempre provocando posicionamentos em diferentes fases da vida da escritora. Ela

\footnotetext{
${ }^{4}$ Documento consultado no espólio de Clarice Lispector da Fundação Casa de Rui Barbosa, na cidade do Rio de Janeiro.

${ }^{5}$ Essa informação Clarice Lispector vai mencionar em diversas entrevistas, inclusive no depoimento que concedeu ao Museu da Imagem e do Som (MIS/RJ), em 20 de outubro de 1976.
} 
mesma chega a se considerar uma charlatã, em crônica ao Jornal do Brasil, na edição de 26 de abril de 19696 :

Como é que eu seria charlatã? Eu fui, e com toda a sinceridade, pensando que acertava. Sou, por exemplo, formada em direito, e com isso enganei a mim e aos outros. Não, mais a mim que a todos. No entanto, como eu era sincera: fui estudar direito porque desejava reformar as penitenciárias do Brasil.

Em outra crônica, publicada também no JB, em 17 de fevereiro de 1973, denominada "O Grupo", ela afirma que a escolha do curso superior foi um erro e se justifica por não ter seguido a carreira de advogada. Tenta encontrar explicação plausível e percebe que lhe falta habilidade, pois nem sequer tem vocação para "lidar burocraticamente com o mais simples papel". Clarice recorda ainda um diálogo com o professor e amigo San Tiago Dantas, que não resiste à curiosidade e pergunta o que ela fora fazer num curso de Direito. E, talvez, o direcionamento para o curso tenha finalmente se elucidado. Direito Penal é a resposta de Clarice e ele retruca: "Ah bem, logo adivinhei. Você se interessou pela parte literária do Direito. Quem é jurista mesmo gosta é de Direito Civil".

\footnotetext{
${ }^{6}$ Parte das crônicas publicadas no Jornal do Brasil foram reunidas no volume A Descoberta do Mundo. Para este artigo, utilizamos a edição de 1984 da Nova Fronteira. Cf. "Charlatões", pp. 280-281. 


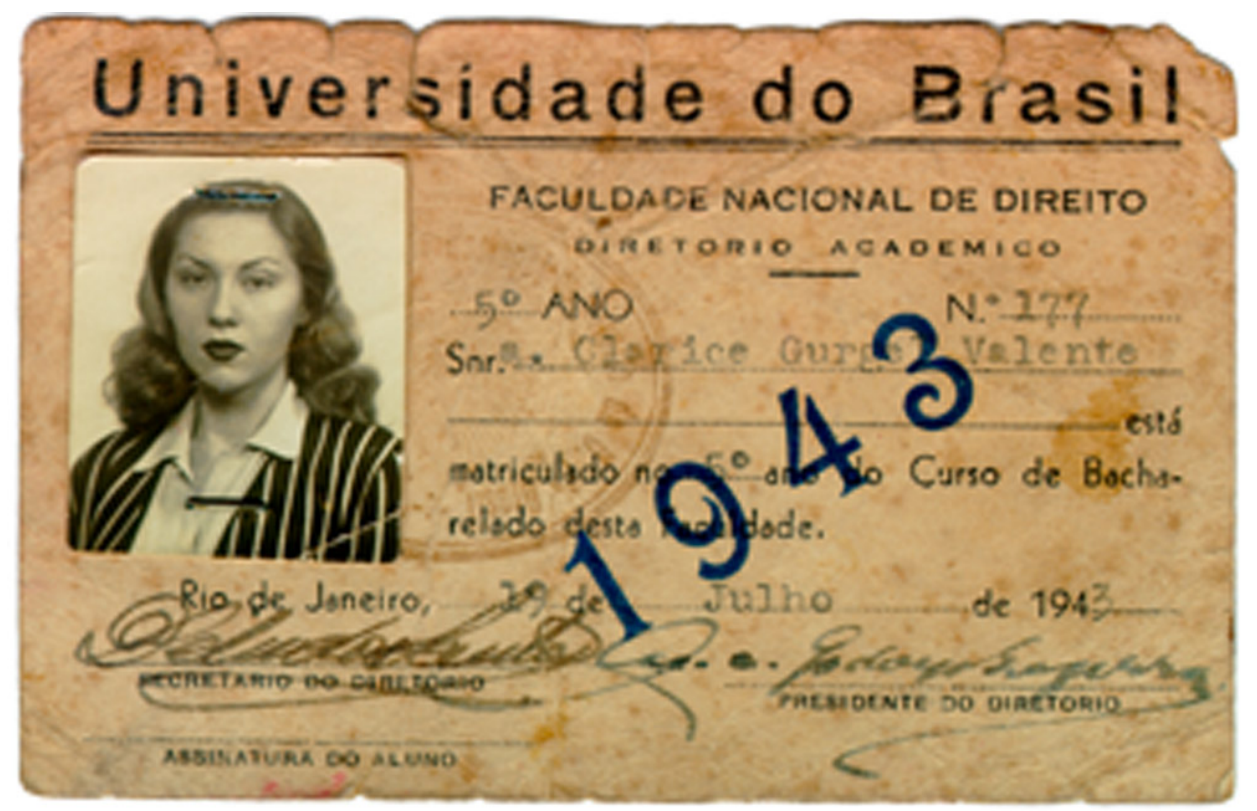

Figura 1 - Carteira de estudante de Clarice Lispector, já com o nome de casada, quando cursava o $5^{\circ}$ ano do Bacharelado de Direito em 1943. Fonte: Fundação Casa de Rui Barbosa.

Clarice Lispector, todavia, não é a única mulher na turma. Ao escrever a crônica "O Grupo", motivada pelo almoço de reencontro com três ex-colegas da Faculdade Nacional de Direito7, a escritora fala que "gostávamos umas das outras". Por isso o reencontro tinha sido alegre, mesmo sem confidências. Mas, ao mesmo tempo melancólico, porque nenhuma delas terminara sendo advogada. Esse tempo gasto em preparo para uma profissão que não foi exercida incomodava Clarice. Um tempo perdido, à toa. Ela, assim, complementa:

Em mim havia um certo estoicismo, em relação a ter tido uma parte de meu passado tão inútil. Ora, mas quantas outras coisas inúteis eu já havia vivido. Uma vida é curta: mas, se cortarmos os seus pedaços mortos, curtíssima fica ela. Transforma-se numa vida feita de alguns dias apenas? Bem, mas é preciso não esquecer que a parte inútil fora, na hora, vivida com tanto ardor (por Direito Penal). O que de algum modo paga a pena.

\footnotetext{
7 O nome da crônica "O Grupo" foi inspirado pelo reencontro com as amigas e também porque a atmosfera do almoço lembrava a do livro e do filme "O Grupo", segundo Clarice. Cf. A Descoberta do Mundo, p. 719.
} 
Mas esse passado não foi inútil como pensa Clarice. É como universitária que ela tem a oportunidade de estabelecer uma rede de relacionamentos que permitirá ampliar sua visão de mundo, além de favorecer a publicação de suas ideias e da literatura que começava a produzir por aqueles tempos.

\section{Reivindicadora de direitos}

San Tiago Dantas parece ter decifrado a charada. Clarice se equivocara na escolha da profissão, que, afinal, procurou atender a um chamado de infância. Quando criança em Recife, era chamada de "a protetora dos animais" por seus familiares. Também bastava para qualquer pessoa ser acusada de algo que imediatamente ela saia em defesa. Devido a esse comportamento, vaticinaram: "vai ser advogada".

[...] eu sentia o drama social com tanta intensidade que vivia de coração perplexo diante das grandes injustiças a que são submetidas as chamadas classes menos privilegiadas. Em Recife eu ia aos domingos visitar a casa de nossa empregada nos mocambos. E o que eu via me fazia como que me prometer que não deixaria aquilo continuar. Eu queria agir. Em Recife, onde morei até doze anos de idade, havia muitas vezes nas ruas um aglomerado de pessoas diante das quais alguém discursava ardorosamente sobre a tragédia social. E lembro-me de como eu vibrava e de como eu me prometia que um dia esta seria a minha tarefa: a de defender os direitos dos outros. (LISPECTOR, Jornal do Brasil, 2-11-1968, p. 13) ${ }^{8}$

É, portanto, sua perplexidade diante das injustiças da vida que leva Clarice a optar pelo curso de Direito na tentativa de reformar não somente as penitenciárias, mas também o mundo. Daí o entusiasmo pelo Direito Penal e a escolha de temas relacionados ao crime, ao proibido, à transgressão, aos excluídos, aos diferentes. Não é por acaso, então, que a estudante escreve o

\footnotetext{
8 A crônica "Literatura e Justiça" foi publicada pela primeira vez em "Fundo de Gaveta", segunda parte do volume A Legião Estrangeira, p.149.
} 
primeiro artigo para $A$ Época, "Observações sobre o fundamento do direito de punir", defendendo a tese de que não há direito de punir, mas tão-só o poder de punir. Os argumentos que a universitária arrola para comprovar a questão de que "o homem é punido pelo seu crime porque o Estado é mais forte que ele" são de ordem subjetiva e expressam a mesma indignação em presença das injustiças sociais em Recife. Para ela, o crime não passa de sintoma de um mal social. A pena simplesmente abafa esse mal, mas não o cura.

Clarice afirma que não há direito de punir pelo simples fato de que "a própria representação do crime na mente humana é o que há de mais instável e relativo". Crime, esclarece, na maior parte das vezes, "significa um ataque a determinada instituição vigente", e assevera:

O que é certo, na questão da punição, é que determinadas instituições, em dada época, sentindo-se ameaçadas em sua solidez com a perpetração de determinados atos, taxa-os como puníveis; muitas vezes nesses atos não há nem a sombra de um delito natural; essas instituições querem apenas se defender.

Para a redatora de $A$ Época, punir representa um resquício do passado, "quando a vingança era o objetivo da sentença". Deveria haver o direito de defender a sociedade contra a reincidência de um crime, mas nesse caso não se trataria mais de "direito de punir" e sim de "dever de punir". Enquanto "punir" significar simplesmente encarcerar o criminoso, em vez de almejar a cura do mal social para impedir outros de cometerem o mesmo delito, então, diz ela em $A$ Época, é "preferível abandonar a discussão filosófica dum 'fundamento do direito de punir', e, de cabeça baixa, continuar a ministrar morfina às dores da sociedade".

O posicionamento de Clarice Lispector repercute no meio universitário e ela é criticada, a ponto de um colega de classe considerar o texto "sentimental"'. Mas, ao publicá-lo na revista acadêmica, a autora acrescenta uma nota explicativa:

\footnotetext{
9 Essa informação é dada pela própria Clarice Lispector, em nota, ao final do artigo. Cf. Clarice na Cabeceira: Jornalismo, p. 70.
} 
Quero esclarecer-lhe que o direito penal move com coisas humanas, por excelência. Só se pode estuda-lo, pois, humanamente. E se o adjetivo "sentimental" veio a propósito de minha alusão a certas questões extrapenais, digo-lhe que não se pode chegar a conclusões, em qualquer domínio, sem estabelecer as premissas indispensáveis.

Clarice, como assinalou San Tiago Dantas, não se comporta como jurista. Redige um artigo que já aponta para a vocação que seguiria: a da literatura. Ela mesma, em entrevista a Pedro Bloch, décadas depois, admite que encarava os assuntos penais de maneira romântica: "Tinha sido levada por leituras que me haviam impressionado. Crime e castigo sempre me provocou muito"10.

Mas, a chamada "visão romântica" sobre assuntos penais, na verdade, não convence Clarice Lispector. Sua forma de entender o crime e o criminoso não se altera. E pela imprensa ela incita o leitor a olhar para uma sociedade hipócrita. Não apenas a olhar, mas a se situar. É tempo, segundo a articulista de A época, de ver "o homem antes de ele ser um doente do crime", propositura defendida pela jovem Clarice de 21 anos na revista discente de 1941 e também pela Clarice de 30 anos quando comenta o caso Caryl Chessman na página feminina "Só para mulheres", do Diário da noite, assinando como Ilka Soares, na sessão "Nossa conversa", em 9 de maio de 1960. Sob a acusação de ser o famoso Bandido da Luz Vermelha (The Red Light Bandit), Chessman foi considerado o responsável por roubos e estupros a casais nas colinas que circundavam Hollywood. Mesmo negando veementemente, até o fim, a autoria dos crimes, Chessman foi condenado, pelo Tribunal de Los Angeles, a respirar um gás mortífero. Indignada com o caso, que mobilizou a opinião pública daquele momento, Clarice Lispector manifesta sua perplexidade diante de uma justiça que se vale do "olho por olho e dente por dente". Para Clarice, essa justiça "mata como médico que desse veneno a um doente por

10 Pedro Bloch, em Vida, Pensamento e Obra de Grandes Vultos da Cultura Brasileira, p. 8. 
que não soubesse que remédio outro lhe dar ou não tivesse no hospital lugar para ele. Uma justiça que é cega, não porque atinja a igualdade, mas porque já se vangloria de não enxergar”.

É importante notar que a opinião de Clarice Lispector sobre esses assuntos também é corroborada por outros juristas. Em relação ao caso Chessman, por exemplo, o famoso criminalista Nelson Hungria, ministro do Supremo Tribunal Federal entre 1951 e 1961, e também professor de Direito Penal na Faculdade Nacional de Direito, em conferência no Centro Acadêmico XI de Agosto, em maio de 1959, afirma:

\begin{abstract}
Para erradicar o mal, não é preciso erradicar o homem. O que cumpre fazer não é matar o homem criminoso, mas o criminoso no homem. A criminalidade não se extingue ou declina com a pena de morte. Ao invés de arrogar-se arbitrariamente o direito de matar, ao Estado incumbe promover a remodelação da própria sociedade, para que se apresentem melhores condições políticas, econômicas e éticas, eliminadoras das causas etiológicas do crime.
\end{abstract}

No segundo texto que publica em $A$ Época, "Deve a mulher trabalhar?", Clarice, motivada pelo trabalho de repórter, que exerce como colaboradora em alguns periódicos cariocas, divulga a enquete que realizou com estudantes do curso de Direito, sobre a atuação da mulher fora de casa. A questão para o início da década de 1940 é sintomática e, sobretudo para a jovem estudante, que concilia as aulas do turno da tarde com as pautas que cobre na Agência Nacional.

Para que possamos compreender melhor a importância dessa enquete, feita de maneira improvisada por uma Clarice Lispector desconhecida, é preciso ter em conta que, a princípio, o fato de a mulher trabalhar não devesse ser um conflito para a jovem estudante, pois, desde Recife, onde os Lispector moraram antes de se mudarem, em 1935, para o Rio de Janeiro, Elisa, a irmã mais velha, sempre trabalhou para ajudar nas despesas, após a morte da mãe 
Mania. Mesmo na capital federal, Elisa cuida logo de prestar concurso para o Ministério do Trabalho e é aprovada. Contratada, mantém esse emprego pelo resto de sua vida, conciliando as funções com a carreira de escritora. Clarice, por sua vez, assim que entra para a Faculdade de Direito, em 1939, trabalha como secretária, primeiramente, em um escritório de advocacia e, depois, em um laboratório. Com a morte do pai, Pedro, em 26 de agosto de 1940, em decorrência de uma cirurgia de vesícula, Clarice começa a trabalhar como redatora e tradutora na Agência Nacional, distribuidora de notícias do DIP. Certamente a condição de ser aluna da Faculdade Nacional de Direito a auxilia na conquista do cargo, que a aproxima de escritores e jornalistas de renome, como Lúcio Cardoso e Antonio Calado, que passam a ser seus colegas. E, dessa maneira, Clarice é inserida nas rodas intelectuais do Rio de Janeiro.

A enquete publicada em $A$ Época mostra-se mais importante pelo texto de abertura do que propriamente pelas respostas dos entrevistados. É na abertura da matéria que a jovem estudante, um tanto quanto à frente daquela década, expressa suas convicções, que se constituirão em linha ideológica para o trabalho com as futuras colunas femininas, como veremos ainda neste artigo.

Logo no primeiro parágrafo de introdução da enquete, Clarice escreve que a temática do trabalho da mulher fora de casa é velha, embora date apenas da Grande Guerra, pelo tanto que foi estudada. "Deve ou não deve ela estender suas atividades pelos vários setores sociais? Deve, ou não, voltar suas vistas também para fora do lar?”, questiona. Na sequência, apresenta as duas possibilidades que se deparam: ou ela segue seu eterno destino biológico ou escolhe livremente seu caminho. "De um lado, a casa, compreendendo filhos e marido, exigindo abnegação constante. De outro, a evolução dos costumes e dos ideais, lançando-a no conhecimento de si mesma e de suas possibilidades", escreve. Clarice demonstra, já nesse momento, ter conhecimento suficiente para dissertar sobre as questões feministas, o que nos leva a admitir que as leituras, contatos e vivências posteriores só fizeram a ratificar no espírito de Clarice o que ela trazia de sua juventude. O texto 
fala também do auxílio que a mulher presta em momentos de crise e da surpresa que foi para o mundo e para a própria mulher saberem que "ela pode”. E, para a jovem estudante é essa descoberta que está na origem de um problema que surge na sociedade e, simultaneamente, de um conflito interior feminino. Ou seja, sabia-se agora que a mulher é detentora de duas tendências opostas que a conduzem a caminhos diversos: uma altruísta e outra egocentrista. A estudante de Direito articula bem a proposta, com desenvoltura. E contextualiza:

No entanto, o evolver dos tempos, com sua função equilibradora, veio, sem construir teorias, resolver o assunto, cortando, a um tempo, as asas do feminismo exaltado e as do conservadorismo arraigado. A mulher moderna estuda. Trabalha. E, suas faculdades despertas e desenvolvidas, constitui seu lar, guiando conscientemente seus filhos. As legislações trabalhistas mais adiantadas abrem um capítulo regulador de suas atividades. Aceitase a nova ordem que, afinal, se trouxe à mulher a alegria de um pouco de liberdade e, sem dúvida, alguns males, também, não foi por ela provocada, mas pelos acontecimentos mundiais e pela consequente instabilidade da vida moderna.

A fala da jovem redatora está sintonizada com uma legislação que olha para um modelo de mulher que destoa daquela que é a abnegada do lar. Percebemos que Clarice entende que o Direito deve acompanhar a evolução dos tempos, amparando, no caso, as mulheres que são impelidas "pelos acontecimentos mundiais" e pela "instabilidade da vida moderna" ao trabalho fora de casa, que acabou lhe trazendo "a alegria de um pouco de liberdade". Justamente, segundo a articulista, pelo tema não ser visto com tanto preconceito, a enquete foi realizada, com o cuidado de equilibrar as opiniões a favor e as contra. Afinal, argumenta Clarice, é na "Faculdade de Direito, onde se aprende a aceitar a evolução e a consolidá-la em leis”, que se reflete o modo de sentir da sociedade. 


\section{O feminismo de Clarice Lispector}

Enquanto cursa a Faculdade de Direito, Clarice Lispector procura trabalho na imprensa carioca. Atua na Agência Nacional e no jornal A Noite. Publica matéria jornalística e literária nos mais representativos periódicos do início da década de 1940, como a revista Vamos Ler! e o jornal literário Dom Casmurro. Órfã, ela se dedica ao cumprimento de pautas e ao novo projeto literário, orientado pelo amigo Lúcio Cardoso, seu colega na Agência Nacional: escrever um romance. Desse modo, toma forma o livro que recebe o título Perto do Coração Selvagem, lançado em 1943. É também em 1943 que Clarice conclui o curso de Direito e se casa com o colega de faculdade Maury Gurgel Valente. Por pouco tempo, continua no Rio de Janeiro até que parte para Belém do Pará antes de iniciar viagem ao exterior, acompanhando o marido em missão diplomática. Mora na Itália, Suíça e Inglaterra.

Mas, em 1952, quando o casal Valente visita o Brasil e permanece no Rio de Janeiro por alguns meses, antes de Maury ser transferido para Washington, nesse intervalo de tempo, de maio a setembro, Clarice retorna ao jornalismo, aceitando convite do amigo Rubem Braga, para fazer parte da equipe do tabloide Comício, em oposição ao governo de Getúlio Vargas. Vale salientar que, além de Rubem Braga, o semanário também é dirigido por Joel Silveira e Rafael Corrêa de Oliveira.

Sob o pseudônimo de Tereza Quadros, Clarice Lispector publica nesta sua coluna feminina alguns rudimentos de crônica em página onde se misturam conselhos de etiqueta, moda, culinária, cuidados com o rosto, postura e tudo o mais que cerca o universo da mulher, mãe e esposa. "Entre Mulheres", nome da coluna, marca, então, em 1952, o ponto de partida dessa nova atividade desempenhada por Clarice na imprensa, que será retomada em outros periódicos sob outros pseudônimos. Alguns anos mais tarde, Clarice será também a Helen Palmer da "Feira de Utilidades" do Correio da Manhã (RJ), de 1959 a 1961. E ainda a ghost writer da atriz e manequim Ilka Soares, na coluna "Só para Mulheres" do Diário da Noite (RJ), de abril de 1960 a março de 1961. 
Protegida pelo pseudônimo de Tereza Quadros, a jornalista, que por aquele tempo concilia os papéis de esposa de diplomata e mãe de Pedro, conversa com a nova leitora sobre coisas simples, revela segredos, apresenta novidades da Europa, ensina como tornar a vida prática. Faz também, seguindo a estética da imprensa feminina, conforme nos ensina Evelyne Sullerot, com que sua companheira de bate-papo se sinta diferenciada, especial, feminina. Clarice, demonstrando conhecer a linguagem e a temática da função jornalística, fará de Tereza Quadros uma amiga íntima e velha conhecida para quem a ler em Comício, apontando em sua prosa alguns inimigos: o tempo, a inexperiência, a falta de informação.

Com autonomia e uma página inteira à disposição, Clarice Lispector faz de "Entre Mulheres" um espaço, não somente para dialogar com a leitora, mas também para divulgar as ideias que traz da Europa e publicar seus contos e crônicas, sem ter de pedir o consentimento de editor. Tais circunstâncias, é importante frisar, permitem aferir diversos aspectos interessantes na leitura atenta da página feminina de Comício, sobretudo em relação a essa Clarice Lispector que chega ao Brasil no início da década de 1950 trazendo na bagagem as experiências vividas como judia em uma Europa marcada pelo nazismo, como escritora que se relacionou com personalidades de vanguarda cultural e como mulher habituada aos requintes e pompas da diplomacia.

A página de Tereza Quadros é marcada por seções, como "Aprendendo a Viver", "Conselhos de minha Vizinha", "Será que Você Sabe", "O que Você não Deve Usar" e "Baú de Mascate". São seções que cuidam em transmitir algum tipo de conhecimento, em tom pedagógico. Mediante o princípio, ensinado por Dulcília Buitoni, de que a imprensa feminina não está preocupada com a atualidade, e sim com a novidade, o conteúdo normalmente gira em torno de moda, beleza, decoração, cuidados com o filho e o marido, culinária e algum tipo de informação que acrescente um quê de civilização. Os tempos começam a mudar e o pós-guerra insta a mulher a atitudes menos conservadoras. Os avanços tecnológicos da indústria e a persuasão de 
campanhas publicitárias consolidam o estereótipo da mulher elegante, bonita e prendada, para afirmar a natureza feminina e o conceito de feminilidade, que deveriam perpassar a imprensa dirigida a mulheres.



Figura 2 - Fac-símile da segunda página feminina "Entre Mulheres”, publicada no semanário Comício, em 22 de maio de 1952. Neste número, a colunista publica "A Irmã de Shakespeare". Fonte: Arquivo pessoal de Aparecida Maria Nunes.

Tereza Quadros confirma ser competente na técnica de escrever sobre assuntos mais amenos. É eclética e deixa escapar certa erudição, ao selecionar trechos literários de autores consagrados. "Entre Mulheres" se permite, portanto, distrair a leitora com narrativas saborosas, como "Um retrato de mulher", de Bernard Shaw, sobre a atriz Sarah Bernhardt, e um fragmento 
de At the bay de Katherine Mansfield. Literatura e jornalismo feminino se fundem na página de Tereza Quadros, que insere contos e crônicas sem autoria, subentendendo ser da colunista. Mas, na verdade, são narrativas de Clarice Lispector inéditas naquele momento, que serão republicadas, com alterações, em livros de contos posteriores. Dessa maneira, Tereza Quadros acaba sendo um alter ego da ficcionista de $A$ Hora da Estrela.

A página "Entre Mulheres" é tão emblemática na produção midiática da escritora, em nossa concepção, que Clarice Lispector chega a transformála ainda em locus para expressar suas inquietações sobre a condição feminina. Apesar de a ficcionista ser discreta em suas manifestações políticas, "Entre Mulheres" passa a ser ainda um espaço onde Clarice introduz propostas ousadas, preocupando-se com os espaços desiguais ocupados pelas mulheres na sociedade, a exemplo da estudante de Direito que foi, escrevendo suas ideias em $A$ Época. Por isso, não é à toa que Tereza Quadros parafraseia o discurso de Virginia Woolf em Comício.

O trecho escolhido faz parte de Um Teto Todo Seu, ensaio literário de Woolf, publicado em 1929, resultado de duas conferências realizadas em estabelecimentos de ensino para mulheres, em Cambridge. As ideias feministas da escritora inglesa são bem claras nessa obra, pois afirma categoricamente que a mulher não escreve a própria vida. Raramente se dedica a um diário, quanto mais a um poema ou peça teatral. Quando muito, escreve cartas. Virginia Woolf denuncia a formação educacional diferenciada entre homens e mulheres e a atribuição de papeis sociais injustos aos sexos. Avança mais: propõe que a mulher tenha dinheiro e um teto próprio para se dedicar a escrever ficção.

Tereza Quadros, na verdade, se apropria do discurso de Virginia Woolf, apesar de apresentá-lo entre as aspas duplas, simulando ser a voz da autora de Um Teto Todo Seu. Mas é a voz do discurso interior de Clarice Lispector que fala, em nítida identificação com as ideias que lá estão. A colunista anuncia de pronto o objetivo do texto, contextualiza, fala das oportunidades oferecidas a Shakespeare e Judith (sua possível irmã), do destino de ambos e 
a tese de que nenhuma mulher, mesmo talentosa, no período elisabetano, poderia ter escrito peças densas e profundas. A discussão sobre a condição feminina é, portanto, apresentada da seguinte forma:

A irmã de Shakespeare ${ }^{11}$

"Uma escritora inglesa - Virginia Woolf — querendo provar que mulher nenhuma, na época de Shakespeare, poderia ter escrito as peças de Shakespeare, inventou, para este último, uma irmã que se chamaria Judith. Judith teria o mesmo gênio do seu irmãozinho William, a mesma vocação.

Na verdade, seria um outro Shakespeare, só que, por gentil fatalidade da natureza, usaria saias. Antes, em poucas palavras, V. Woolf descreveu a vida do próprio Shakespeare: freqüentara escolas, estudara em latim Ovídio, Virgílio, Horácio, além de todos os outros princípios de cultura; em menino, caçara coelhos, perambulara pelas vizinhanças, espiara bem o que queria espiar, armazenando infância; como rapazinho, foi obrigado a casar um pouco apressado; essa ligeira leviandade deu-lhe vontade de escapar e ei-lo a caminho de Londres, em busca de sorte. Como tem sido bastante provado, ele tinha gosto por teatro. Começou por empregar-se como "olheiro" de cavalos, na porta de um teatro, depois imiscuiu-se entre os atores, conseguiu ser um deles, freqüentou o mundo, aguçou suas palavras em contato com as ruas e o povo, teve acesso ao palácio da rainha, terminou sendo Shakespeare.

E Judith? Bem, Judith não seria mandada para a escola. E ninguém lê em latim sem ao menos saber as declinações. Às vezes, como tinha tanto desejo de aprender, pegava nos livros do irmão. Os pais intervinham: mandavamna cerzir meias ou vigiar o assado. Não por maldade: adoravam-na e queriam que ela se tornasse uma verdadeira mulher. Chegou a época de casar. Ela não queria, sonhava com outros mundos. Apanhou do pai, viu as lágrimas da mãe. Em luta com tudo, mas com o mesmo ímpeto do irmão, arrumou uma trouxa e fugiu para Londres. Também Judith gostava de

${ }^{11}$ Cf. o texto no fac-símile da página de Tereza Quadros, figura 2. 
teatro. Parou na porta de um, disse que queria trabalhar com os artistas foi uma risada geral, todos imaginaram logo outra coisa. Como poderia arranjar comida? Nem podia ficar andando pelas ruas. Alguém, um homem, teve pena dela. Em breve ela esperava um filho. Até que, numa noite de inverno, ela se matou. "Quem", diz Virginia Woolf, "poderá calcular o calor e a violência de um coração de poeta quando preso no corpo de uma mulher?"

E assim acaba a história que não existiu."

Ao escolher Virginia Woolf, Clarice Lispector manifesta a voz de seu discurso interior, atenta às condições socioculturais que impedem a mulher de transitar na sociedade desempenhando o papel que deseja para si. Tereza Quadros, portanto, não transforma explicitamente suas páginas femininas em espaço de denúncia sobre a condição feminina. Mas, ao emprestar o discurso de outrem, principalmente selecionando falas de mulheres, aponta caminhos que são questionadores para sua leitora, que pode até não ter informação suficiente para saber quem foi de fato Virginia Woolf, por exemplo. Afinal, conforme nos explica Mikhail Bakhtin, aquele que faz uso da enunciação de outra pessoa "não é um ser mudo, privado da palavra, mas ao contrário um ser cheio de palavras interiores" (1986, p. 147).

Em “A Irmã de Shakespeare", em se tratando do dilema de Judith, a leitora de Comício poderia se identificar com as dificuldades que uma mulher talentosa enfrenta para trilhar um caminho próprio. Ou melhor, como a sociedade conduz a mulher para determinados destinos, porque a adoravam "e queriam que ela se tornasse uma verdadeira mulher". Cerzir meias e vigiar o assado são somente algumas atribuições do ser mulher.

\section{Lispector publica Beauvoir}


Clarice Lispector não destoa do paradigma Felicidade-Saúde-Beleza na composição das colunas que escreve. Cuidadosamente, ela sabe aliciar a leitora para a página feminina, com textos triviais e marcadamente inseridos no sistema patriarcal, mediante o arquétipo de feminilidade burguês de 1952 . A leitora de "Entre Mulheres" é a casada (ou que pretende casar-se), com filhos (ou que os deseja), que cuida da casa e se cuida para o marido (ou namorado). Tudo conforme e consoante ao establishment.

A Clarice Lispector de 1952, na verdade, é uma ativista dissimulada. Prova disso é que ela insere muitas ideias do livro $O$ Segundo Sexo na página de Tereza Quadros, em momento no qual a autora, Simone de Beauvoir (19081986), não é publicada no Brasil. O curioso é que, ao criar as seções para a página, idealiza uma com receitas, não de cozinha, mas do que é "ser mulher". Esta seção recebe o nome de "Aprendendo a Viver"12 e tem o propósito deliberado de fundar um espaço conscientizador, catártico, psicoterápico e educador, mediante à exposição de casos ou de narrativas de como deve ser a mulher.

Nessa seção, a colunista privilegia a receita do saber viver, emprestando, para isso, o ponto de vista de filósofos e escritores para corroborar certas discussões. Simone de Beauvoir, Stekel, Barlow, Rilke, Howard Whitman e Fénelon são autores nos quais Tereza encontra saberes que considera oportunos para atualizar a mulher brasileira sobre sua condição feminina. Mas Clarice Lispector não conta que a escolha de certos trechos se dá a partir de O Segundo Sexo, que traduz para Comício.

Aliás, quando ainda estava na Europa, Clarice deve ter lido Simone no original, porque o primeiro volume foi editado na França em maio de 1949 e somente será traduzido no Brasil em 196013. Contudo, em 1952, é provável que Clarice Lispector tenha se precavido a não citar a fonte dos textos retirados da obra de Simone de Beauvoir, temendo alguma reação negativa.

\footnotetext{
${ }^{12}$ Cf. nos fac-similes, figuras 2 e 3.

${ }^{13}$ Antes do lançamento, porém, trechos do livro publicados na revista Les Temps Modernes, dirigida por Beauvoir e Jean-Paul Sartre, alcançaram enorme sucesso.
} 
Embora a edição em livro na Europa de $O$ segundo sexo, logo na primeira semana de lançamento, tenha atingido a marca de 22 mil exemplares vendidos, opositores se mobilizaram para que a obra fosse retirada de várias livrarias. A resistência levou a obra, em 1956, a entrar para a lista de livros proibidos pela igreja católica, o Index, e de ser proibida em Portugal e na Rússia.

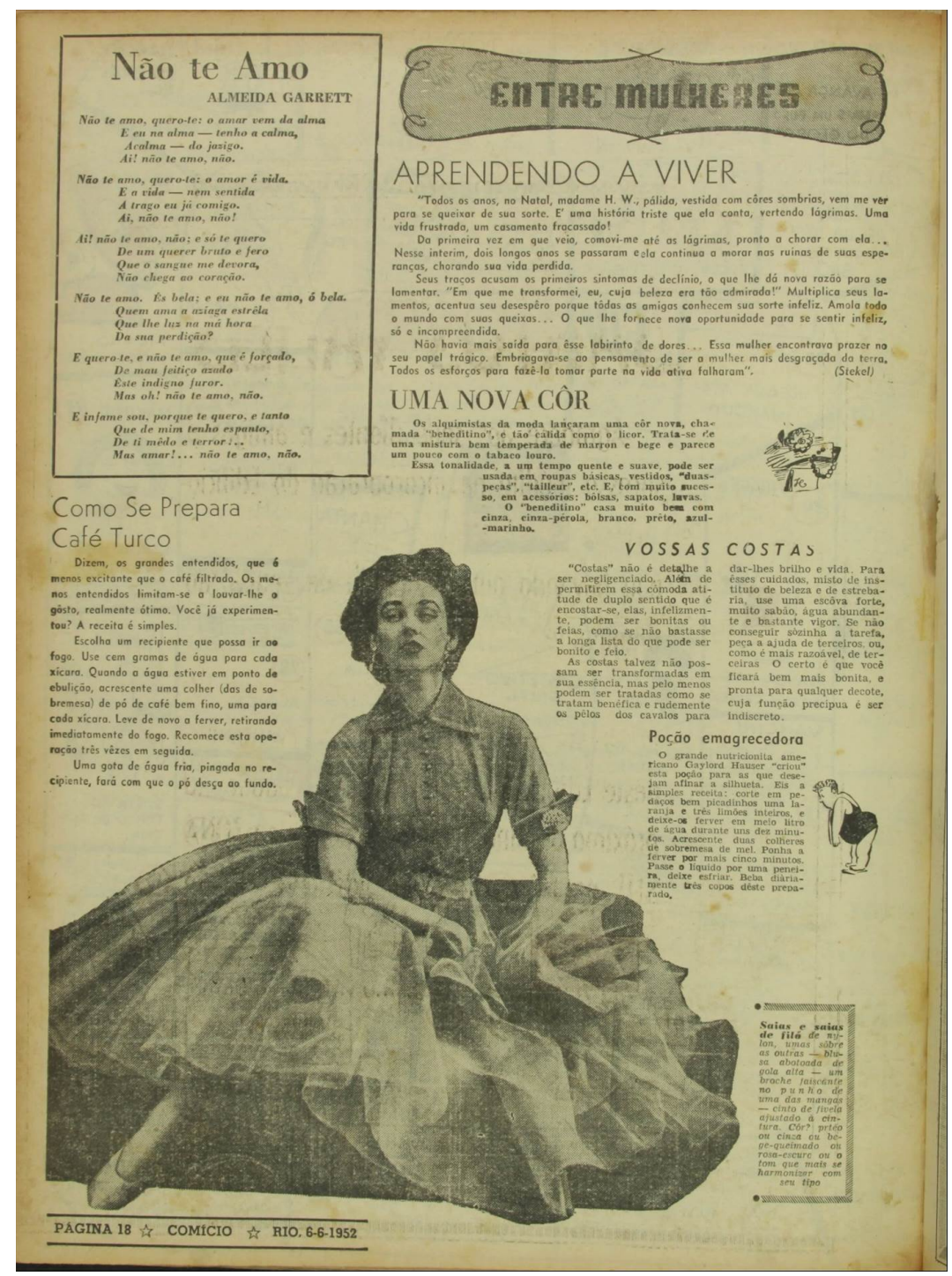

Figura 3 - Fac-símile da quarta página feminina "Entre Mulheres". Neste número, datado de 06 de junho de 1952, a colunista publica na seç̧ão "Aprendendo a Viver" um trecho extraído do livro $O$ Segundo Sexo, de Simone de Beauvoir. Fonte: Arquivo pessoal de Aparecida Maria Nunes.

Então, quando Clarice Lispector escreve "Entre Mulheres", em 1952, demonstra ter tido acesso à obra da escritora francesa e que, ao traduzir 
vários trechos do volume, atualiza a leitora carioca sobre ideias de vanguarda que circulavam na Europa relacionadas à condição das mulheres na sociedade, além de demonstrar simpatia pela causa feminista.

Um dos casos apresentados por Tereza Quadros na seção “Aprendendo a Viver" foi o da senhora H.W.14, relatado pelo psiquiatra Wilhelm Stekel, um dos primeiros seguidores de Sigmund Freud, considerado ainda como o seu mais notável discípulo pela capacidade hábil de descobrir "material recalcado". Stekel desprezava linguagem técnica em seus relatos. Preferia o texto simples para narrar os casos clínicos, muitas vezes romanceados, sob a influência perceptível de Dostoiévski sobre sua escrita. Tanto que diversas narrativas de casos clínicos de Stekel, sobretudo da publicação A Mulher Fria, foram selecionadas por Simone de Beauvoir para ilustrar as discussões propostas em $O$ Segundo Sexo. O caso clínico de H.W., incluído no segundo volume, do capítulo "A Narcisista" da terceira parte, foi um dos escolhidos para justificar o perfil "mater dolorosa", quando a mulher se julga ser a mais desgraçada do mundo. Clarice Lispector, então, traduz o fragmento transcrito abaixo, explicitando a autoria entre parênteses, mas omitindo a fonte que utilizou. Também não introduz a narrativa tampouco debate. Eis:

Todos os anos, no Natal, madame H. W., pálida, vestida com cores sombrias, vem me ver para se queixar da sua sorte. É uma história triste que ele conta, vertendo lágrimas. Uma vida frustrada, um casamento fracassado! Da primeira vez em que veio, comovi-me até as lágrimas, pronto a chorar com ela...Nesse ínterim, dois longos anos se passaram e ela continua a morar nas ruínas das suas esperanças, chorando sua vida perdida. Seus traços acusam os primeiros sintomas de declínio, o que lhe dá nova razão para se lamentar. "Em que me transformei, eu, cuja beleza era tão admirada!" Multiplica seus lamentos, acentua seus desesperos porque todas as amigas conhecem sua sorte infeliz. Amola todo o mundo com suas queixas... O que lhe fornece nova oportunidade para se sentir infeliz, só e incompreendida. Não havia mais saída para esse labirinto de

\footnotetext{
14 Publicado em 06 de junho de 1952.
} 
dores...Essa mulher encontrava prazer no seu papel trágico. Embriagavase ao pensamento de ser a mulher mais desgraçada da terra. Todos os esforços para fazê-la tomar parte na vida ativa falharam. (Stekel) ${ }^{15}$

Simone de Beauvoir, em relação a este caso clínico, explica que a mulher que se vitimiza não se realiza na vida e se sente incompreendida, porque as pessoas que a cercam não reconhecem sua singularidade. Então, cria uma personagem na qual se vê constantemente: a da mulher que encontra prazer no seu papel trágico.

Ao trazer à tona rostos de mulheres em narrativas com elementos psicológicos, extraídos em sua maioria de O Segundo Sexo, Tereza Quadros demonstra que adota a linha editorial feminista, para reforçar a consolidação do paradigma "ser mulher". Quem sabe, por cuidado, sabendo que as ideias de Simone de Beauvoir poderiam impedir a leitora mais conservadora de se olhar e questionar o próprio rosto, opta por omitir a autoria desses escritos e do contexto em que foram retirados. No entanto, fica evidente que Lispector leu Beauvoir com muito interesse e que o fato de publicar alguns extratos na página de Tereza Quadros ratifica o assentimento ao discurso feminista.

No capítulo "A Mulher Independente", da quarta parte intitulada "A Caminho da Libertação", do segundo volume de O Segundo Sexo, Simone de Beauvoir argumenta que a conquista das liberdades cívicas, como o direito ao voto, permanece abstrata quando a mulher não dispõe de autonomia econômica, pois somente o trabalho pode assegurar-lhe a liberdade concreta (1967, p. 449). É desse capítulo que Clarice Lispector vai escolher um fragmento com a assinatura de Simone de Beauvoir para a nona edição de "Entre Mulheres”, como parte da seção "Aprendendo a Viver”, sem, contudo, dar-lhe um título, uma introdução, um comentário ou discorrer sobre a importância da autora.

\footnotetext{
15 Importa esclarecer que os trechos de obras de outros autores que constam da página feminina de Comício, principalmente retirados de $O$ Segundo Sexo, foram traduzidos provavelmente por Clarice Lispector. Há algumas variações de texto que podem ser constatadas entre o que Clarice publicou e a edição brasileira dessa obra de Beauvoir, que seria traduzida somente anos mais tarde.
} 
Estou convencida de que a grande maioria dos mal-estares e doenças que atingem as mulheres tem causas psíquicas. É por causa da tensão moral de que eu falei, por causa de todas as tarefas que assumem, das contradições do ambiente no qual se debatem, que as mulheres estão constantemente cansadas, até o limite das forças. Isso não significa que seus males sejam imaginários: eles são reais e devorantes como a situação que exprimem. Mas a situação não depende do corpo, é este que depende dela. Assim, a saúde não prejudicará o trabalho da mulher quando esta tiver na sociedade o lugar de que ela precisa. Pelo contrário, o trabalho a ajudará poderosamente a obter um equilíbrio físico, não lhe permitindo que se preocupe com este sem cessar. (Le Deuxième Sexe, Simone de Beauvoir)

O fragmento pertence a uma discussão em que se ponderava até que ponto a menstruação poderia ser impedimento para o trabalho da mulher. Havia, na época, a mentalidade que a mulher deveria se resguardar, o que seria impeditivo para o desempenho de tarefas fora do lar. Mas Beauvoir afirmou que os incômodos podem ser minimizados, se a mulher estiver satisfeita e motivada. Acusou, no texto, que os mal-estares e o cansaço femininos tinham causa psíquica, decorrente de tensão moral.

\section{Considerações finais}

Debruçar sobre a produção de Clarice Lispector na imprensa carioca, quando ela ainda era uma jovem estudante, se faz necessário. Jornais e revistas eram considerados por ela como meio para a divulgação de seus escritos juvenis. Uma maneira de dar forma à vida de escritora que projetara. Muitos periódicos, na era Vargas, dedicavam algum espaço para novos escritores. Clarice Lispector, então, aproveita tal oportunidade para buscar junto de editores a publicação de seus contos.

Raymundo Magalhães Junior, ao escrever “Alegrias de um Padrinho Literário"16, lembra que Clarice Lispector era quase uma menina quando o

${ }^{16}$ Cf. Clarice na Cabeceira: Jornalismo, pp. 15-16. 
procurou para solicitar o emprego de tradutora. Nunca havia publicado nada, segundo o editor. Mas sabia que podia, ressalta. "E escrevia mesmo, com um bom gosto, uma propriedade, uma graça, que já então revelavam nela a futura romancista". Com o consentimento de Magalhães Junior, a jovem de 20 anos, consegue espaço para publicar a literatura e o jornalismo que fazia.

Reveste-se, portanto, de interesse, não somente pelo valor de resgate, o registro dessas primeiras incursões de Clarice Lispector em órgãos de imprensa, mas também para traçar o perfil da jovem nascida em Tchetchelnik. Percebemos que, embora alguns contos fossem bem acabados e outros, não - aspecto comum para quem apenas tem o impulso de escrever ficção, sem preparo ou orientação especializada - havia nela o entusiasmo e uma temática recorrente: os conflitos das relações afetivas entre casais. "Triunfo", publicado na revista Pan ${ }^{17}$, e "Eu e Jimmy", na revista Vamos Ler! ${ }^{18}$, ambos em 1940, antecipam a presença de protagonistas decididas, colocando em xeque, às vezes de forma bem-humorada, a crítica em relação à subserviência da mulher no amor. A mesma preocupação norteia outros contos que escreve (mas não publica) entre 1940 e 1941, que serão reunidos postumamente, por Olga Borelli, no volume A Bela e a Fera (1979) ${ }^{19}$.

São muitas - e esparsas - as publicações de Clarice Lispector no período compreendido entre 1940 e $1943^{20}$. No entanto, o que nos motivou a centrar os estudos nos artigos de $A$ Época e nas narrativas curtas de "Entre Mulheres" foi justamente a questão de serem textos pouco examinados, em que pese a importância de darem visibilidade à anuência por causas feministas.

Clarice Lispector nunca assumiu em vida uma postura feminista. Preferiu ficar discreta. Mas o viés feminista está evidente nessa produção inicial da estudante de Direito, sobretudo quando o contexto cultural do Brasil

\footnotetext{
17 Edição de 25 de maio de 1940.

18 Edição de 10 de outubro de 1940.

19 Os contos "O Delírio", "A Fuga" e "História Interrompida" são de 1940; "Gertrude Pede um Conselho", "Obsessão" e "Dois Bêbados" são de 1941.

${ }^{20}$ Em 1943, Clarice se casa, publica Perto do Coração Selvagem e conclui o curso de Direito. Com sua ida para a Europa, ela interrompe provisoriamente sua carreira na imprensa carioca.
} 
dos anos 1940 instigava matéria que acentuasse as questões de pátria e família. Clarice não se intimidou. Escreveu o que achou necessário.

A cautela talvez tenha sido a escolha, quando já com trinta e dois anos de idade retorna ao Rio de Janeiro, depois de praticamente nove anos vividos numa Europa pós-guerra. Mais amadurecida, a Clarice que aceita ser Tereza Quadros de uma página feminina, encontra motivação para falar mais de perto a um outro tipo de leitora. Talvez, desejasse contribuir com o que tinha aferido de leituras e vivências. Simone de Beauvoir foi uma preferência desde sempre. Em carta escrita em Berna, datada de 30 de junho de 1947, para Elisa Lispector, ela se compromete a enviar, sem falta, para a irmã, o livro que prometera da "escritora, filósofa, feminista francesa".

Percebemos, e este fato nos instiga a aprofundar esta pesquisa, que os textos de uma escritora ainda adolescente não destoam de toda a produção literária e jornalística de Clarice Lispector. Se atentarmos bem, veremos que o ângulo pelo qual a jovem universitária viu a vida e as questões relacionadas com o "ser feminino" perpassam por sua obra. Por isso, não será leviano afirmar que Clarice em Comício tinha a preocupação de elevar a leitora de jornal a um nível mais elevado de consciência sobre sua condição de mulher em uma sociedade machista e patriarcal. Mas, como em sua literatura, a marca da dissimulação também se faz presente na página de Tereza Quadros, ao compartilhar textos sintomáticos de $O$ Segundo Sexo, sem citar a fonte.

\section{Referências}

BAKHTIN, Mikhail./VOLOCHINOV, Valenti Nikolaiévitch. Marxismo e Filosofia da Linguagem. São Paulo: Hucitec, 1986.

BEAUVOIR, Simone. O Segundo Sexo - Fatos e Mitos. São Paulo: Difusão Europeia do Livro, 1980.

BEAUVOIR, Simone. O Segundo Sexo - a Experiência Vivida. São Paulo: Difusão Europeia do Livro, 1967. 
BLOCH, Pedro. Vida, Pensamento e Obra de Grandes Vultos da Cultura Brasileira. Rio de Janeiro, Bloch, 1989.

BUITONI, Dulcília Helena Schroeder. Mulher de Papel: a Representação da Mulher pela Imprensa Feminina Brasileira. São Paulo: Loyola, 1981.

BUITONI, Dulcília Helena Schroeder. Imprensa Feminina. São Paulo: Ática, 1986. Princípios, 41.

CANDIDO, Antonio, Prefácio. In: Miceli, Sergio. Intelectuais e Classe Dirigente no Brasil (1920-1945). São Paulo: Difel, 1979, p. IX-XIII.

GOTLIB, Nádia Battella. Clarice: uma Vida que se Conta. São Paulo, Ática, 1995.

LISPECTOR, Clarice. A Descoberta do Mundo. Rio de Janeiro: Nova Fronteira, 1984.

LISPECTOR,Clarice. A Legião Estrangeira. Rio de Janeiro: Editora do Autor, 1964.

MICELI, Sergio. Intelectuais e Classe Dirigente no Brasil (1920-1945). São Paulo: Difel, 1979.

MICELI, Sergio. Intelectuais à Brasileira. São Paulo: Cia das Letras, 2001.

Montero, Teresa (Org.). Minhas Queridas. Rio de Janeiro: Rocco, 2007.

MORIN, Edgar. Cultura de Massas no Século XX (O Espírito do Tempo). Rio de Janeiro - São Paulo: Forense, s.d.

NUNES, Aparecida Maria Nunes (Org.). Clarice Lispector na Cabeceira: Jornalismo. Rio de Janeiro: Rocco, 2012.

NUNES, Aparecida Maria. Clarice Lispector Jornalista: Páginas Femininas \& Outras Páginas. São Paulo: Editora Senac São Paulo, 2006. 
SILVEIRA, Joel. "O Estado Novo e o Getulismo". Entrevista a Gilberto Negreiros. In: Folha de São Paulo - 9/01/1979.

SULLEROT, Evelyne. La Presse Féminine. Paris: Armand Colin, 1963.

Recebido em março de 2019. Aprovado em abril de 2019. 